\title{
Clastic compaction unit classification based on clay content and integrated compaction recovery using well and seismic data
}

\author{
Zhong Hong $^{1} \cdot$ Ming-Jun Su${ }^{1} \cdot$ Hua-Qing Liu ${ }^{1} \cdot$ Gai Gao $^{2}$
}

Received: 17 March 2015/Published online: 7 November 2016

(C) The Author(s) 2016. This article is published with open access at Springerlink.com

\begin{abstract}
Compaction correction is a key part of paleogeomorphic recovery methods. Yet, the influence of lithology on the porosity evolution is not usually taken into account. Present methods merely classify the lithologies as sandstone and mudstone to undertake separate porositydepth compaction modeling. However, using just two lithologies is an oversimplification that cannot represent the compaction history. In such schemes, the precision of the compaction recovery is inadequate. To improve the precision of compaction recovery, a depth compaction model has been proposed that involves both porosity and clay content. A clastic lithological compaction unit classification method, based on clay content, has been designed to identify lithological boundaries and establish sets of compaction units. Also, on the basis of the clastic compaction unit classification, two methods of compaction recovery that integrate well and seismic data are employed to extrapolate well-based compaction information outward along seismic lines and recover the paleo-topography of the clastic strata in the region. The examples presented here show that a better understanding of paleo-geomorphology can be gained by applying the proposed compaction recovery technology.
\end{abstract}

Zhong Hong

hongzhong_go@petrochina.com.cn

1 PetroChina Research Institute of Petroleum Exploration and Development (RIPED)-Northwest, Lanzhou 730020, Gansu, China

2 Research Institute of Exploration and Development, PetroChina Changqing Oilfield Company, Xi' an 710018, Shaanxi, China

Edited by Jie Hao
Keywords Compaction recovery · Porosity-clay contentdepth compaction model · Classification of lithological compaction unit - Well and seismic data integrated compaction recovery technology

\section{Introduction}

Paleo-geomorphology controls not only the spatial distribution of a depositional system, but also to some extent determines the source, reservoir, and seal units. The effect of mechanical compaction is one of several factors influencing hydrocarbon formation and evolution, with other factors including erosion effects, tectonic activity, diagenesis, and abnormal pressure. As the compaction process is extremely complex, it has garnered wide interest. A considerable number of compaction correction models have been established. Athy (1930) proposed an empirical exponential model of porosity and depth based on the condition of normal pressure, which served as an extensive reference for numerous basins around the world. Falvey and Middleton (1981) held that the evolution of porosity cannot be characterized by a classical exponential model at shallow depths. As a result, they proposed a compaction function based on the relationship between porosity and upper-layer load. In deep strata, porosity does not necessarily change as depth increases. Taking this phenomenon into account, Athy's exponential model was improved ( $\mathrm{Li}$ and Kong 2001). Li et al. (2000) proposed a compaction correction method based on the principle that the grain volume and mass of formation should remain constant, which has resulted in deep debate among Chinese investigators (e.g., Qi and Yang 2001; Li 2001). Schon (2004) proposed a logarithmic function of compaction between porosity and depth. 
The influence of lithology on porosity rarely has been considered in previous compaction correction studies. Actually, the compaction characteristics of clastic rocks are considerably different as the lithology changes. Consequently, among the present studies, dividing the clastic sedimentary units into just two lithologies, mudstone and sandstone, is too much of a simplification. Such a method is not able to represent and generalize the compaction history of mixed grain-size lithologies such as muddy siltstone and silty mudstone, in addition to pure mudstone and pure sandstone. A clastic compaction study considering only the influence of lithology toward the porosity was undertaken by Ramm and Bjørlykke (1994), who found that according to the statistical relationship between mineral content and porosity, porosity had a higher correlation with the clay-content index. Subsequently, a compaction model involving porosity, depth, and clay-content index has been developed.

Based on former research, a depth compaction model has been proposed that takes porosity and clay content into account to be reliably assessed in terms of rock-physics theory and laboratory experiments. To improve the precision of compaction correction studies, a clastic lithological compaction unit classification method based on clay content has been designed to identify lithological strata and establish compaction units (Fig. 1). Also, to assess the method for industrial applications, two integrated methods are proposed that use both well and seismic data to evaluate 3-D compaction characteristics in clastic strata.

\section{Theoretical basis of clastic compaction unit classification based on clay content}

Usually, qualitative methods are used to classify clastic compaction units. This is done in terms of well log interpretations that classify lithologies into categories such as pure sandstone, pure mudstone, muddy siltstone, and silty mudstone. In this way, porosity-depth evolution curves can be obtained for various lithologies. However, this method is time-consuming, which makes its wide implementation difficult in industrial practice. In light of this, an automatic optimization classification method based on clay content is proposed to identify various lithological compaction units. The feasibility of the method and its validation are discussed in this paper in terms of rock-physics theory and rock-physics laboratory tests.

\subsection{Ideal binary clastic mixture model}

The ideal binary clastic mixture model characterizes the inherent correlation, as well as the quantitative functional relationship, between clay content and porosity (Thomas and Stieber 1975, 1977); explicit studies have also been

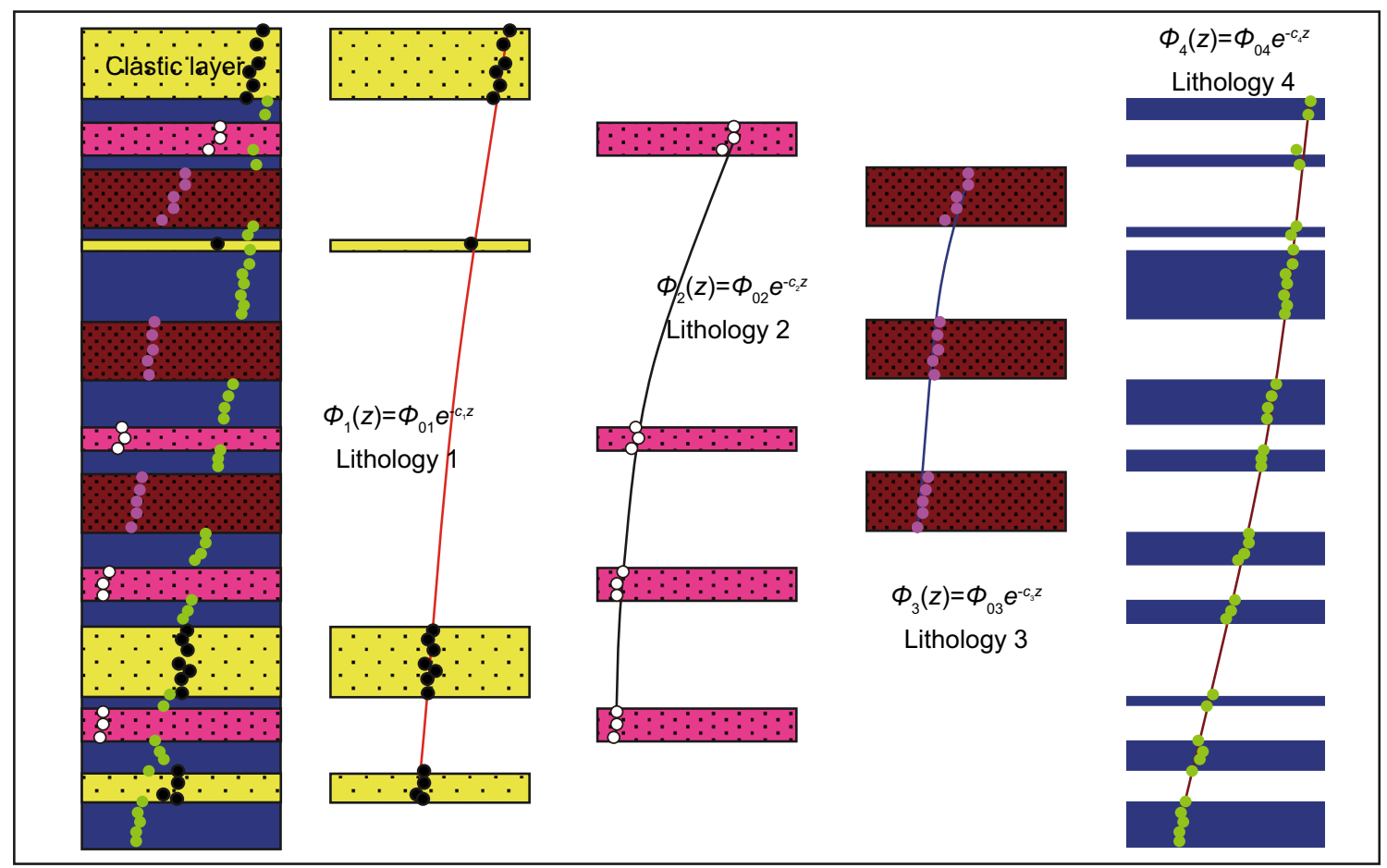

Fig. 1 Schematic map of clastic lithological compaction unit classification 
conducted by several others (e.g., Pedersen and Norda 1999; Mavko 2009; Dvorkin et al. 2014).

Figure 2 shows an ideal binary mixture model. $\phi_{\mathrm{ss}}$ is the critical porosity of pure sandstone, $\phi_{\mathrm{sh}}$ is the critical porosity of pure shale, and $C$ is clay content. When the clay particles fill the pore space between grains in a sandstone, some simple equations can be obtained.

Specifically, for $0 \leq C \leq \phi_{\mathrm{ss}}, \phi=\phi_{\mathrm{ss}}-\left(1-\phi_{\mathrm{sh}}\right) C$, and for $\phi_{\mathrm{ss}} \leq C \leq 1, \phi=\phi_{\mathrm{sh}} C$.

When clay particles serve as part of the framework in sandstone, $\phi=\phi_{\mathrm{ss}}+\phi_{\mathrm{sh}} C$.

This rock-physics model assumes that the sand is clean and homogeneous with a constant porosity and that any change in porosity owing to cementation or sorting is ignored. Practically, even though the formation and evolution of porosity are extremely complex, the ideal binary mixture model is able to simply describe the relationship between porosity and clay content for different clastic lithologies.

\subsection{Rock-physics laboratory relationship between clastic porosity and clay content}

Yin's rock-physics experiments presented a qualitative relationship between porosity and clay content under different pressures (Yin 1992). Figure 3a shows that with different pressures (i.e., different depths), the relationship between porosity and clay content presents a V-shape with an obvious inflection point. This is similar to the ideal binary mixture model. Also, as pressure (depth) increases, the V-shape exhibited by the porosity and clay content is preserved. The experiment shows that although porosity changes, due to mechanical compaction as d epth increases, the porosity and clay content still maintain a regular relationship. The experiment also shows that the higher the

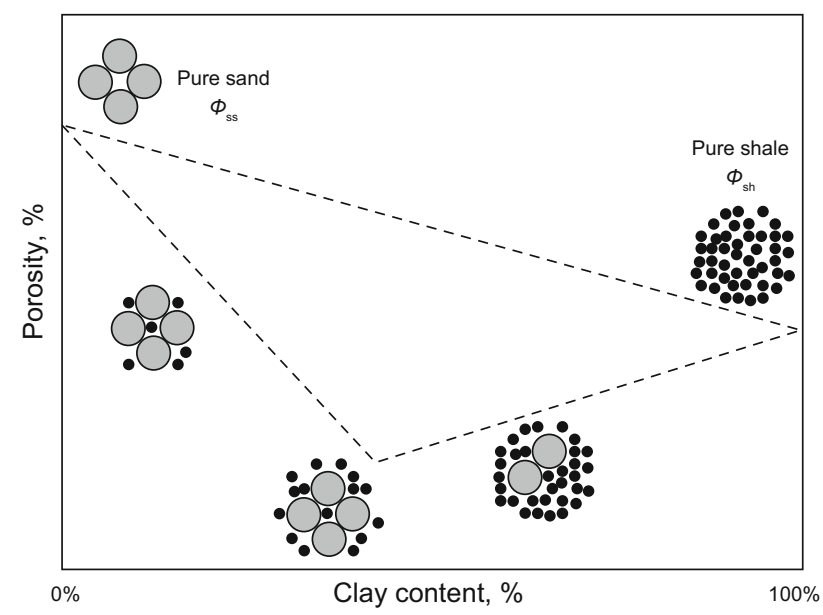

Fig. 2 Ideal binary mixture model (revised according to references of Mavko 2009; Dvorkin et al. 2014) clay content is, the more distinct will be the change in porosity as pressure increases; additionally, the mechanical compaction effect will be more intense. This conforms to the practical compaction characterization of clastic rocks.

Porosity data for specific clay contents under different pressures (Fig. 3a) are selected to map the cross-plot between pressure and porosity. Figure $3 \mathrm{~b}$ shows the evolution of porosity versus pressure for pure sandstone, pure mudstone, and a mixed lithology with $50 \%$ clay content. In this way, the rock-physics experiments illustrate that lithologically independent compaction histories can be identified based on clay content.

As a whole, clay content does not change and has no trend in depth. Based on clay content, it is possible to link compaction relationships for the same lithology at different depths. Also, in terms of not only intrinsic features but also dynamic evolution, the porosity and clay content of clastic rocks have an inherent connection between each other. Consequently, it is valid and feasible to classify clastic compaction units based on clay content.

\section{Classification method for clastic compaction units based on clay content}

\subsection{Calculation of initial porosity}

The initial porosity is defined as the porosity of sediments at the earth's surface directly after deposition. In the exponential function model of porosity and depth, the initial porosity has a significant influence on the compaction recovery. When initial porosity changes by $10 \%$, the resulting estimated thickness after compaction recovery may differ by more than 10\% (Yang and Qi 2003). The formation of initial porosity is extraordinarily complex, and it varies according to depositional background. The initial porosity is affected not only by grain size, sorting, sphericity, roundness, and filling of sediment, but it also involves grain assemblage and consolidation ( $\mathrm{He}$ et al. 2002).

The initial porosity can be obtained through direct experimental measurements (Atkins and McBride 1992; Beard and Weyl 1973; Pryor 1973) or numerical simulations (Zaimy and Rasaei 2013; Fawad et al. 2011; Alberts and Weltje 2001; Harbaugh et al. 1999; Syvitski and Bahr 2001); however, this is a time-consuming process. In industrial practice, He et al. (2002) proposed a method in which the initial porosity is assigned to fall within a reasonable range of values. Then, on the basis of an assigned porosity within the range, residuals of fitted porosities and original porosities are calculated. An initial porosity is subsequently selected from the range as the one with the smallest residual. Yang and Qi (2003) proposed a method 

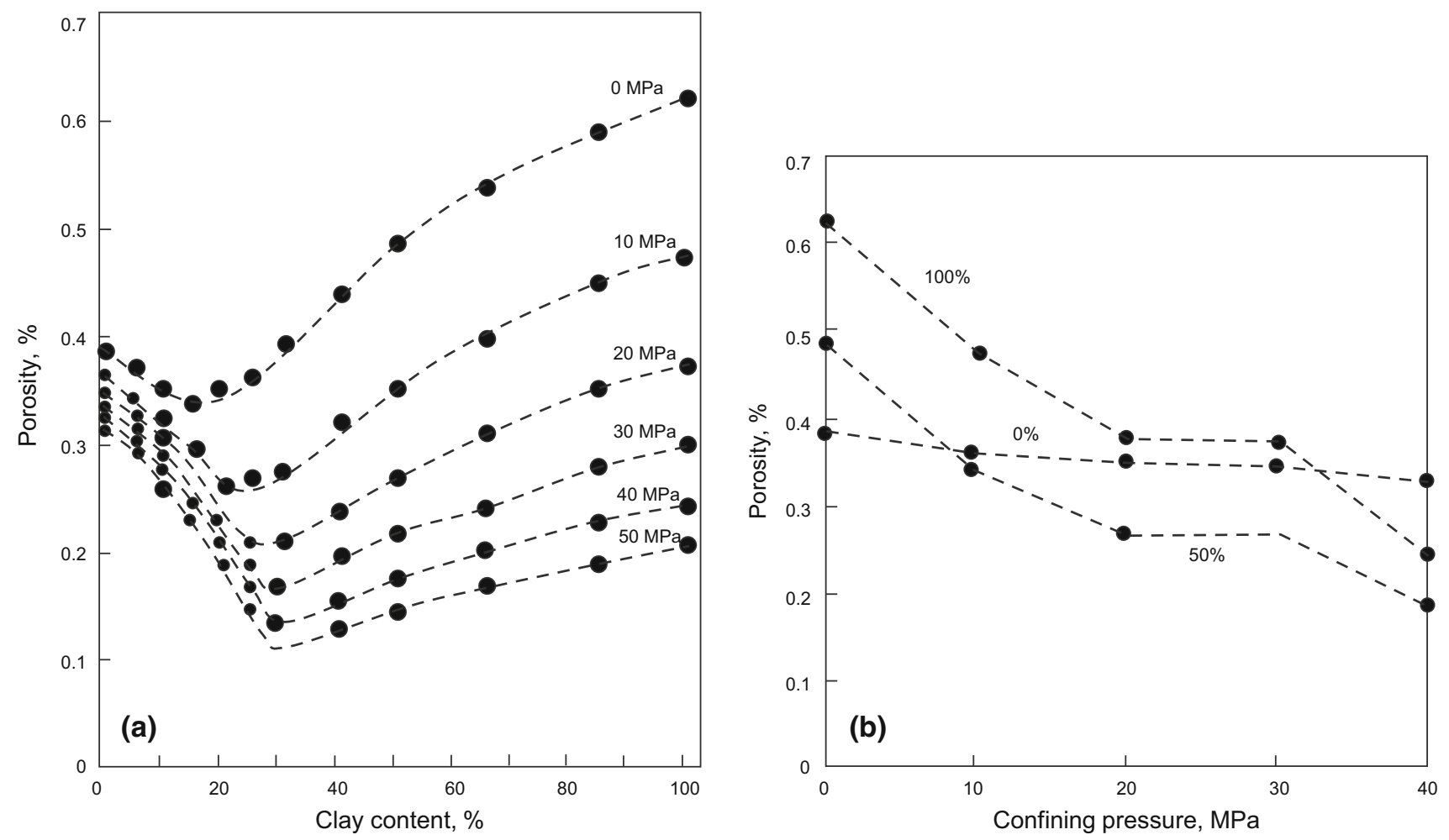

Fig. 3 Rock-physics experiment result maps for the relationship between clay content and porosity (Fig. 3a: relationship map for clay content and porosity under different pressures; Fig. 3b: relationship map for clay content and pressure with different lithologies, Yin 1992)

for directly assigning the initial porosity by either analyzing the grain-size and sedimentary characteristics, or by direct measurements in the laboratory.

Being influenced by the complications of porosity evolution and the reliability of porosity data, the initial porosity fitted by the practical porosity (the porosity value of practical data) always exceeds the critical porosity (it is defined as a porosity that separates mechanical and acoustic behaviors into two distinct domains) of pure shale or sand. Therefore, it is necessary to constrain the initial fitted porosity. Based on a choice of appropriate porosity data, this paper proposes a method for obtaining the initial porosity constrained by the ideal binary clastic mixture model.

First, primary porosity data ought to be selected as reasonably as possible by excluding porosity influenced by tectonic activity, diagenesis effects, and abnormal pressures. Also, because it is calculated by an ideal binary mixture model, the theoretical initial porosity can constrain the fitted initial porosity. For example, when clay particles fill the pore space in a sandstone, the theoretical porosity can be calculated. Specifically, for $0 \leq C \leq \phi_{\mathrm{ss}}$, $\phi=\phi_{\mathrm{ss}}-\left(1-\phi_{\mathrm{sh}}\right) C$, whereas for $\phi_{\mathrm{ss}} \leq C \leq 1, \phi=\phi_{\mathrm{sh}} C$. The fitted porosity may be regarded as unreasonable when it exceeds or is less than an appropriate value (e.g., 20\%) of the theoretical porosity of the ideal binary mixture model. As a result, the theoretical porosity that regard the fitted data can be considered as the initial porosity. Besides, when the fitted initial porosity is within an appropriate range, the fitted initial porosity ought to be used.

\subsection{Methods}

Based on clay content, a method for identifying lithological compaction units was designed to integrate the proposed method above for calculating initial porosity (see flow chart in Fig. 4). The specific procedures followed are outlined below.

\section{Step 1 Data permutation}

The data (depth, clay content, porosity) are permuted into units $(X(1), X(2), X(3), X(4), \ldots$.$) according to the$ clay content from minimum to maximum with a selected window length (e.g., 5\%-15\%, 15\%-25\%, 25\%-35\%, $35 \%-45 \%, 45 \%-55 \%, \ldots$ with a window length of $5 \%$ ).

Step 2 Data combination

Combine the data units into groups [e.g., $\mathrm{X}(1),(\mathrm{X}(1)$, $\mathrm{X}(2)),(\mathrm{X}(1), \mathrm{X}(2), \mathrm{X}(3)),(\mathrm{X}(1), \mathrm{X}(2), \mathrm{X}(3), \mathrm{X}(4))]$ (i.e., $5 \%-15 \%, 5 \%-25 \%, 5 \%-35 \%, 5 \%-45 \%, 5 \%-55 \%, \ldots)$. 


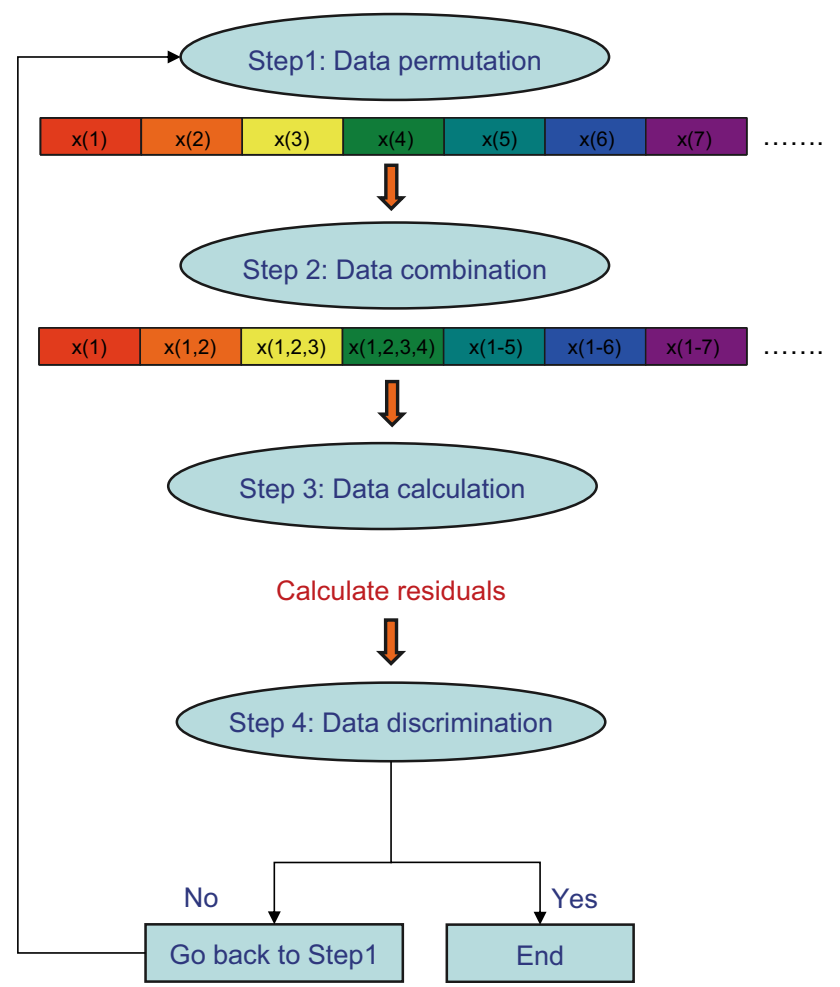

Fig. 4 Flowchart showing automatic classification of clastic compaction units based on clay content

\section{Step 3 Calculation}

Fit the original data from different groups according to the exponential model of porosity and depth $\left(\phi(z)=\phi_{0} e^{-c z}\right)$ to obtain the initial porosity $\left(\phi_{0}\right)$ and compaction coefficient $(c)$ for each group. Also, the average residual $(\mathrm{Rm})$ of each group ought to be returned. $R m$ is the average residual between practical porosity data and fitted porosity data.

$R m=\sum_{i=1}^{n}\left(\varphi_{\text {real }(i)}-\varphi_{\text {fitting }(i)}\right)^{2} / n$

In the equation, $\varphi_{\text {real }(i)}, \varphi_{\text {fitting }(i)}$ are practical porosity and fitted porosity with an index of $i . n$ is the total number of porosity data.

Step 4 Data discrimination

Discriminate the separation group with the minimum average residual among all the groups. Return to Step 2 and calculate the remaining data after the separation group.

For example, if group $[\mathrm{X}(1), \mathrm{X}(2), \mathrm{X}(3)]$ has the minimum average residual, then calculate from $X(4)$ based on step 2, i.e., (X(4)), (X(4), X(5)), (X(4), X(5), X(6)), (X(4), $\mathrm{X}(5), \mathrm{X}(6), \mathrm{X}(7)), \ldots$

Step 5 Calculate to the last group unit

The proposed method regards the size of the average residual as a criterion to judge the precision of the compaction correction for the study. To some extent, the minimum average residual corresponds to the highest precision of the compaction recovery result that we can obtain. Also, the size of the average residual is a criterion that can classify clastic lithological compaction units based on clay content. The method followed in step 4 shows that the separation group, along with the minimum average residual, can be considered as a compaction unit. On the whole, the average residual derived by applying the clastic lithological compaction unit classification technology is less than or equal to that obtained when no clastic lithological compaction units are classified. This means that the precision of the compaction correction based on the proposed methods can be considerably improved.

\subsection{Case study}

Programming for the proposed method of clastic compaction unit classification based on clay content has been conducted successfully. A large amount of well log data, including neutron porosity and clay-content measurements from the Qikou Sag, was employed to test the feasibility of the proposed method. The well log data were derived from the clastic layers of the Minghuazhen, Guantao, Dongying, and Shahejie Formations. To illustrate the success of this process, consider a typical well. First, porosity data needed to be selected. Abnormal porosity data or porosities that obviously deviate from the normal trend, probably within the abnormal pressure section, were excluded. Then, the selected data containing porosity, clay content, and depth were assessed by the program.

Figure 5 and Table 1 show the results. The blue points are input porosity data with various clay contents, whereas the red points are fitted porosity data. Before applying the proposed method, the average residual between the original porosity and fitted porosity was about 47.3 . The automatic compaction unit classification method divided the lithologies into three categories. The average residual of each category is less than 47.3. The practical application illustrates the feasibility of the proposed method and the need to lithologically classify the various compaction units.

\section{Integrated well- and seismic-data compaction recovery method}

To propagate well-based compaction information into the data assessment, two compaction recovery methods that integrate well and seismic data are proposed. One is based on 3-D clay-content data, and the other one is a 3-D interpolation correction based on compaction degree parameters. 


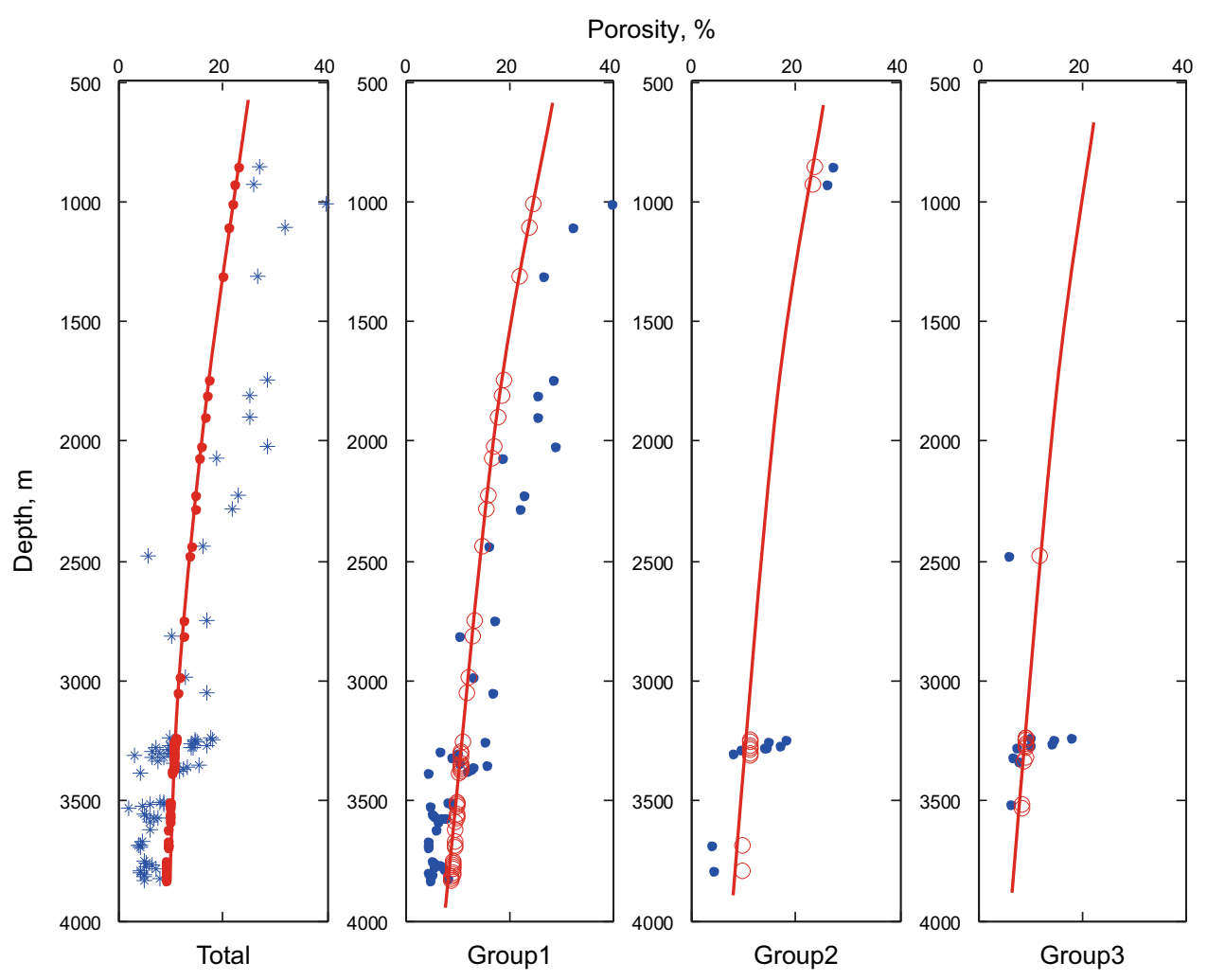

Fig. 5 Automatic classification of clastic lithological compaction units based on the clay content of a single well

Table 1 Automatic classification of clastic lithological compaction units

\begin{tabular}{llllll}
\hline & Lower bound of clay content, $\%$ & Upper bound of clay content, $\%$ & Initial porosity, \% & Compaction coefficient & Fitted residual \\
\hline Original & 3 & 48 & 30 & 0.00032 & 47.3 \\
Group 1 & 3 & 19.9 & 35.9 & 0.00036 & 25.8 \\
Group 2 & 19.9 & 25.5 & 31 & 0.00030 & 22.3 \\
Group 3 & 25.5 & 48 & 27.4 & 0.00038 & 26.3
\end{tabular}

\subsection{Compaction recovery method based on 3-D clay- content data}

Lithological compaction units identified in well data were determined by assessing their respective clay contents. Then, 3-D clay-content seismic inversion data were incorporated to regionally propagate the 1-D compaction information from the wells in plan view. The detailed calculation procedures are as follows (Fig. 6):

Step 1 Acoustic impedance inversion

First, a seismic acoustic impedance inversion should be conducted.

Step 2 Clay-content inversion based on a probabilistic neural network
This method is based on the statistical relationship between acoustic impedance from seismic data and clay content from wells. Usually, the acoustic impedance and the sand content correlate positively. Therefore, a probabilistic neural network (PNN) method is applied to acquire a nonlinear statistical relationship between the acoustic impedance of a borehole side seismic trace and the sand content derived from a well log curve. A 3-D sand-content inversion cube then can be obtained by propagating the statistical relationship to the whole acoustic impedance inversion cube. A clay-content inversion cube then can be conveniently produced.

Step 3 Lithological compaction units determined for multiple wells 


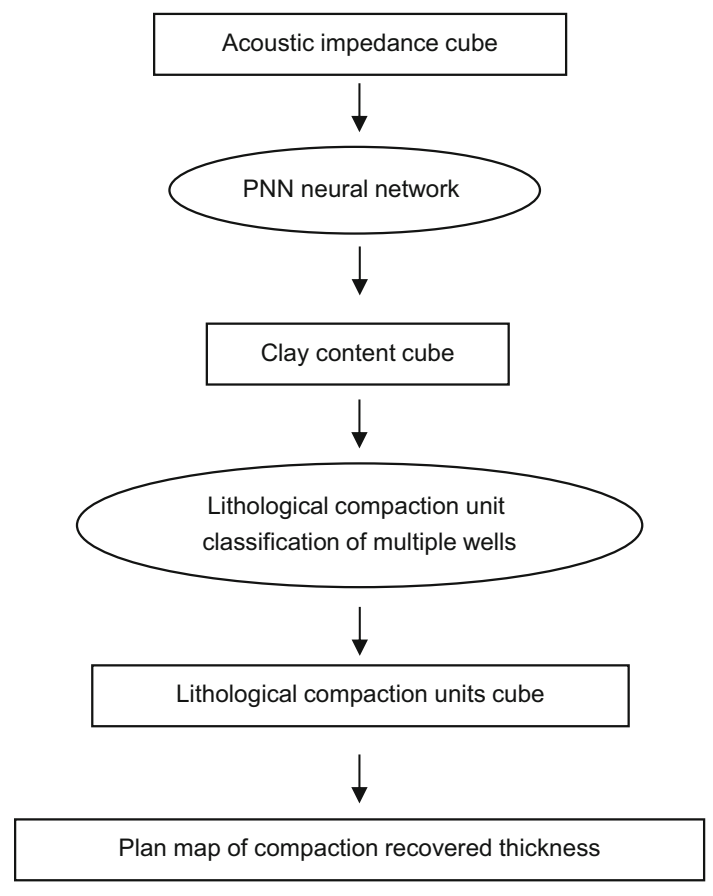

Fig. 6 Flowchart of compaction recovery method based on 3-D claycontent data

The method for characterizing clastic compaction units based on clay content was then applied by assessing integrated well log data for multiple wells, including porosity and clay-content data, to classify lithological compaction units.

Step 4 Calculation of a lithological compaction unit cube

Based on the clay-content range of the classified lithological compaction units (Step 3), a clay-content inversion cube can then be transferred into a lithological compaction unit cube containing a set of compaction units.

Step 5 Calculation of compaction history

Based on the porosity-depth exponential model, the initial porosities and compaction coefficients for the various compaction units, as along with the 3-D lithological compaction unit cube in the depth domain, are integrated to calculate paleo-geomorphic thickness. The programming designed to do this involves two main components.

(1) During the process of stratal compaction, the rock matrix volume remains constant. The porosity-depth exponential model of $\phi(z)=\phi_{0} e^{-c z}$ was applied to calculate $H_{\mathrm{s}}$ for the strata matrix thickness $\left(z_{1}, z_{2}\right.$ separately represent the top and bottom depth of the present strata; i.e., the top and bottom depth of the corresponding compaction units; $\phi_{0}, c$ represent the initial porosity and compaction coefficient of the compaction unit)
$H_{\mathrm{s}}=z_{2}-z_{1}-\frac{\phi_{0}}{c}\left(e^{-c z_{1}}-e^{-c z_{2}}\right)$.

The strata thickness during the compaction process can be calculated by:

$H=z_{4}-z_{3}=H_{\mathrm{s}}+\frac{\phi_{0}}{c}\left(e^{-c z_{3}}-e^{-c z_{4}}\right)$,

where $z_{3}, z_{4}$ separately represent the top and bottom depth of the strata during the compaction process; $H$ is the corresponding strata thickness; when $z_{3}$ is zero, the $H$ represents the paleo-thickness).

(2) As the initial porosity and compaction coefficient of each lithological compaction unit are available, they are combined with the top and bottom depths to calculate the thickness of each lithological compaction unit during the deposition process. Finally, the paleo-geomorphic thickness can be recovered in plan view.

\subsection{Compaction recovery method based on the plan- view interpolation of compaction correction parameters}

The compaction correction parameters of wells were calculated by applying the compaction unit characterization method based on clay content. Then, the compaction correction parameters are interpolated laterally. It is both economical and efficient to develop a compaction recovery thickness map by integrating stratal thickness and the plane map of the compaction parameter. The detailed calculation procedure follows (Fig. 7).

Step 1 Data quality control

The clay-content data come in two types: well log data and interpretations based on well log data. It is necessary to calibrate these two data sets to ensure that their differences can be ignored. The well data should be abandoned if the clay content determined for these two types differs considerably.

Step 2 Well-based lithological compaction unit characterizations

The clastic compaction unit characterization method based on clay content was applied by using quality-controlled porosity and clay-content data to classify the lithological compaction units.

Step 3 Well-based compaction correction degree calculation

The compaction correction degree value for each well should be calculated (i.e., compaction corrected thickness/ original strata thickness). 


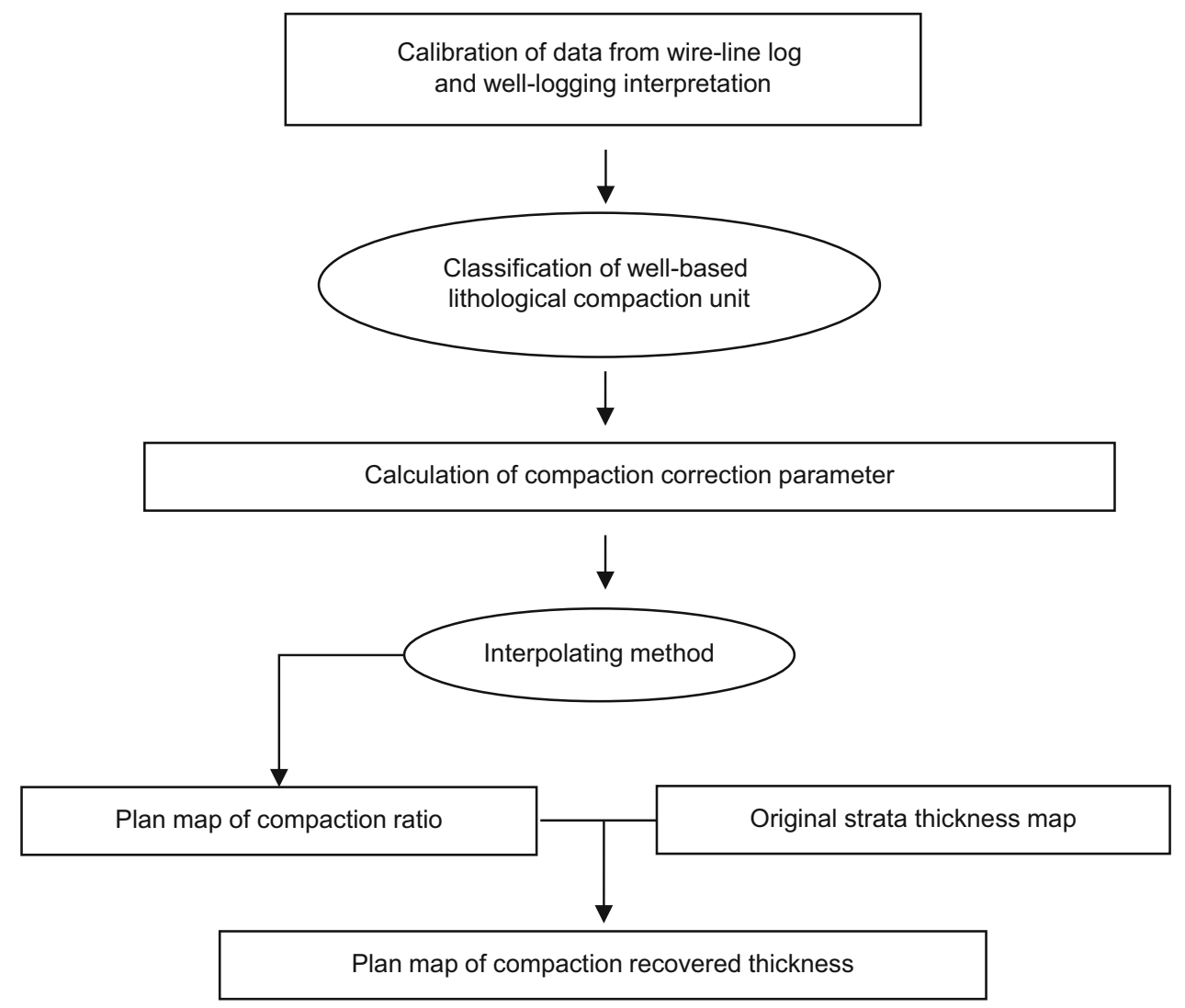

Fig. 7 Flowchart of the compaction recovery method based on a plan-view interpolation of the compaction correction degree parameter

\section{Step 4 Plan-view interpolation}

When the compaction recovery parameters for the wells have been obtained, an interpolation method, e.g., Kriging, should be employed to obtain a plan-view distribution map of the compaction correction parameter.

Step 5 Mapping compaction recovered thickness

A time domain thickness map of target horizons can be obtained through seismic data interpretation. The thickness map in the time domain then can be transferred into the depth domain with the use of a time-depth model. By multiplying the compaction correction degree parameters in the map by the thicknesses in the depth domain, a plan map of compaction recovered thicknesses eventually can be obtained.

\section{Case studies}

\subsection{Case study of a compaction recovery method based on 3-D clay-content data}

A 3-D seismic survey, covering an area of $100 \mathrm{~km}^{2}$ in the Qinan Sag, contains a complete series of clastic Tertiary deposits, including the Kongdian, Shahejie, Dongying, Guantao, and Minghuazhen Formations (from bottom to top). The fracture system within the sag is not developed within the seismic survey, so the influence on porosity evolution attributed to the fracture system largely can be eliminated.

\subsubsection{Identification of lithological compaction units within the wells}

The porosity data were selected with the aid of a cross-plot of porosity and depth values. The simple principle behind the selection of porosity data is to exclude obviously abnormal values such as those from sections where the pressure was unusually high. The porosity data for a group of wells were jointly assessed by the proposed compaction unit classification method. Figure 8 and Table 2 show the resulting lithological compaction units separated into three groups. As no porosity data were available for mudstone in the study area, lithologies with clay contents ranging from $57 \%$ to $100 \%$ were regarded as mudstone. According to a previous local study (Gui 2008), the compaction coefficient of mudstone is 0.000686 . 


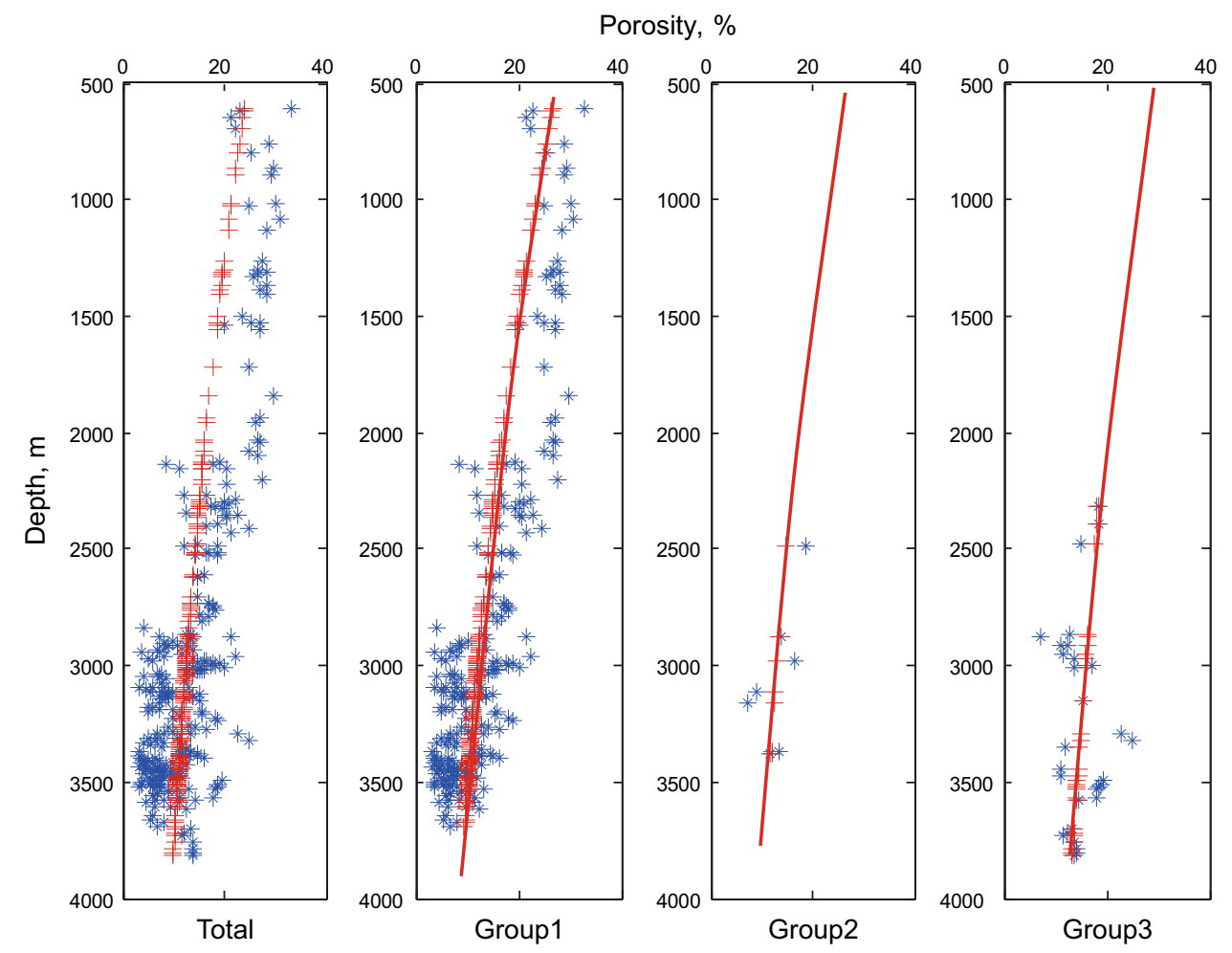

Fig. 8 Automatic classification of the clastic compaction units based on clay content for multiple wells

Table 2 Automatic classification of the clastic compaction units in the study area

\begin{tabular}{llllll}
\hline & Lower bound of clay content, $\%$ & Upper bound of clay content, \% & Initial porosity, \% & Compaction coefficient & Fitted residual \\
\hline Group 1 & 0 & 35 & 32.6 & 0.0003333 & 23.2 \\
Group 2 & 35 & 40.5 & 24.9 & 0.0002155 & 10.3 \\
Group 3 & 40.5 & 57 & 29.3 & 0.0002049 & 15.7 \\
Mudstone & 57 & 100 & 47.1 & 0.000686 \\
\hline
\end{tabular}

\subsubsection{Calculation of a lithological compaction unit cube in the depth domain}

The study region consists of a 3-D post-stack seismic data volume. To calculate the compaction of lithological units, such as the $\mathrm{Es}_{1}^{\mathrm{Z}}$ member, for example, the explicit calculation procedures are as follows.

(1) Seismic acoustic impedance inversion was conducted on the targeted $\mathrm{Es}_{1}^{\mathrm{z}}$ member horizon in the seismic data.

(2) Based on well log data (acoustic impedance and sand content), the nonlinear relationship between the sand content and acoustic impedance was obtained by applying a neural network method.

(3) Based on a nonlinear relationship between acoustic impedance and sand content, the sand content within the 3-D seismic cube was calculated accordingly (Fig. 9a).

(4) According to a 3-D time-depth model for the region, the sand content in the 3-D seismic volume was transformed from the time domain into a 3-D claycontent seismic volume in the depth domain (Fig. 9b).

(5) Finally, by applying the lithology compaction unit information from the Table 2, a 3-D lithology compaction unit seismic cube in the depth domain was derived from the clay-content cube. Figure 9c shows that there are four distinct lithology compaction units.

(6) The compaction correction thickness (Fig. 10) can be calculated based on the related procedure in Step (5). 


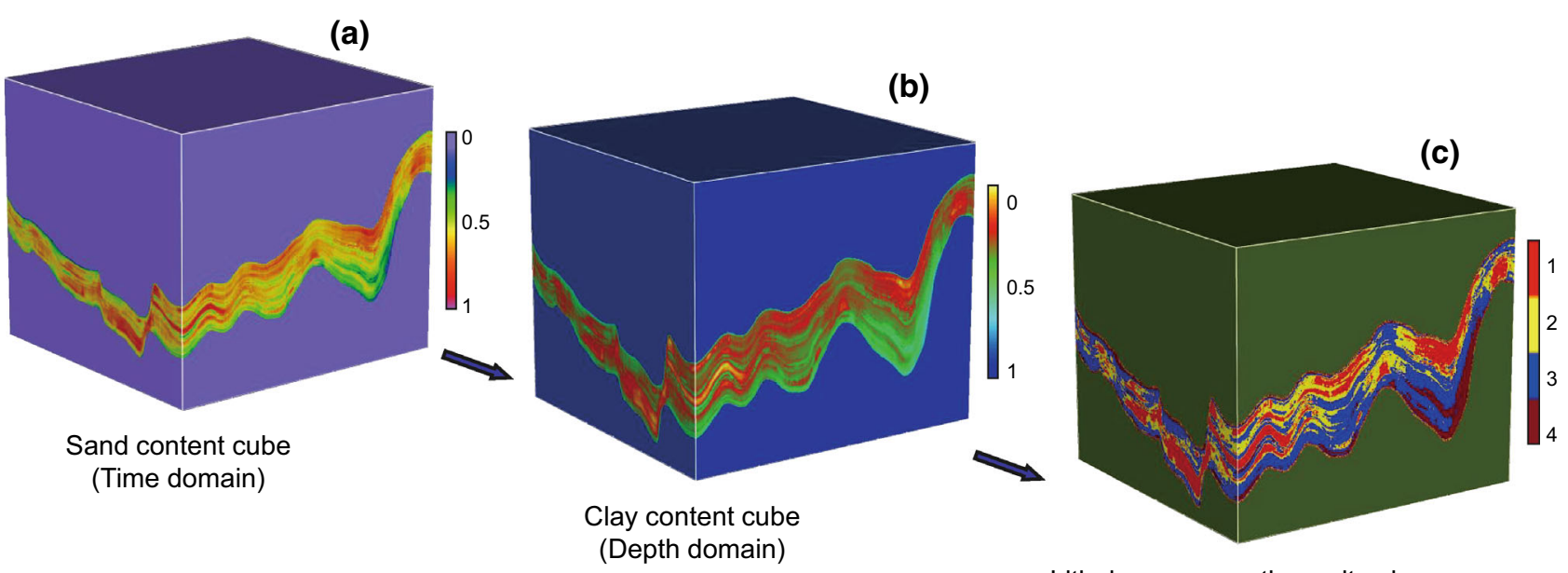

Lithology compaction unit cube (Depth domain)

Fig. 9 Calculation of the lithology compaction unit cube for $\mathrm{Es}_{1}^{\mathrm{z}}$

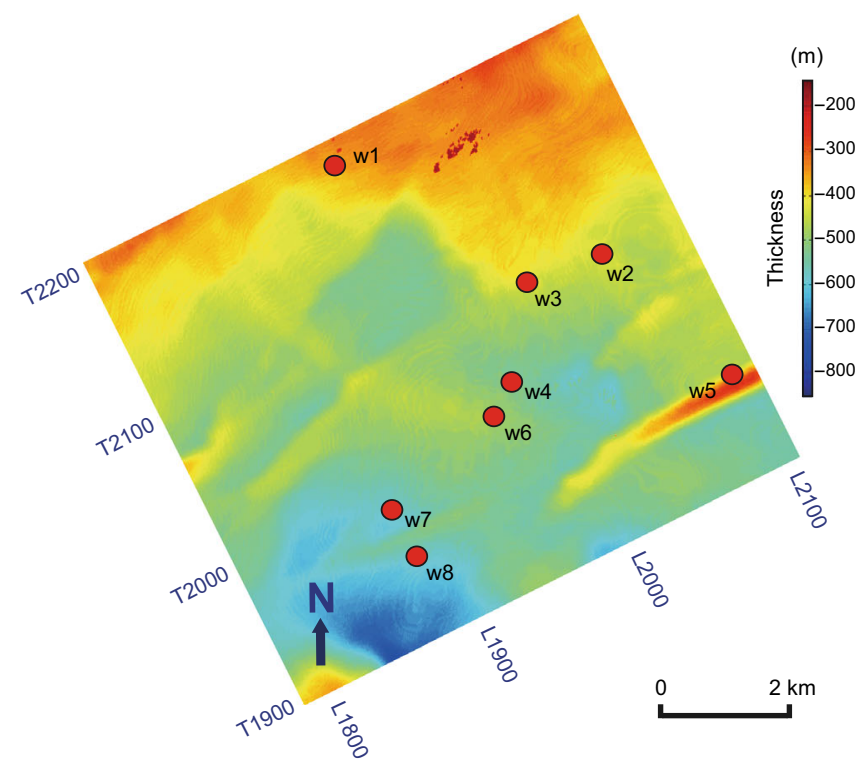

(a)

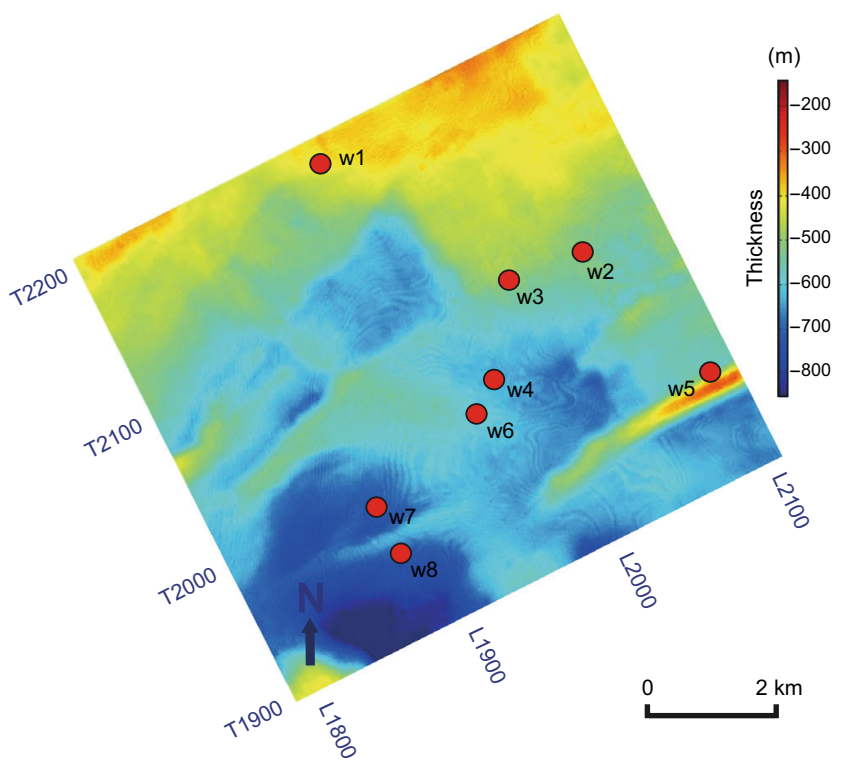

(b)

Fig. 10 Plan view of the recovered paleo-geomorphic thickness of the $\mathrm{Es}_{1}^{\mathrm{z}}$ member of the study area (a without compaction recovery, $\mathbf{b}$ after compaction recovery)

\subsubsection{Analysis of compaction recovery results}

When compaction recovery was applied, the difference in paleo-geomorphic thickness was remarkable. In terms of tectonic geometry, the trend of the post-compaction recovery was almost the same as the original geometry. The inverse phenomenon of tectonic geometry does not occur. The trend in thickness change only presents a slight difference. Relatively high positions become higher, while shallow positions become deeper. Take the geomorphology of W7 and W8, for example. After compaction recovery, the paleo-geomorphology becomes deeper and has steeper slopes. In this case, the $\mathrm{Es}_{1}^{\mathrm{z}}$ member of the study area does not belong to a region of facies change in which the vertical lithology varies rapidly. Therefore, the "topographic inverse" phenomenon of tectonic geometry would not occur after compaction recovery. Yet as a whole, the test of the method based on 3-D clay-content data has proven its feasibility.

\subsection{Case study of the plan-view interpolation-based method}

A $400 \mathrm{~km}^{2}$ 3-D seismic survey located in the Qibei Sag contains a complete series of clastic Tertiary deposits, 

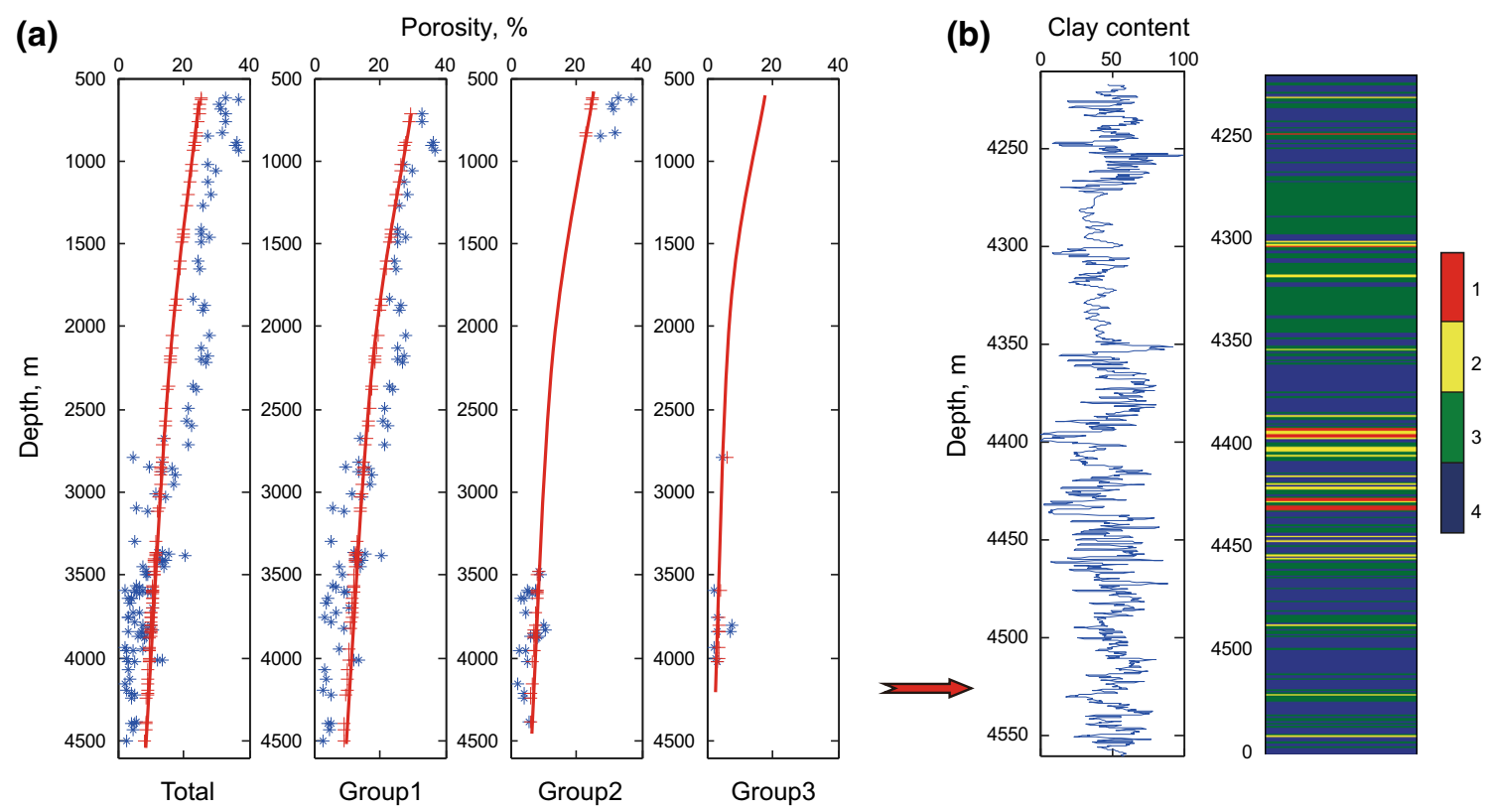

Fig. 11 Calculation of compaction degree for a single well

including the Kongdian, Shahejie, Dongying, Guantao, and Minghuazhen Formations (from bottom to top). Again, the regional fracture system is not developed within the seismic survey, so the influence on porosity evolution attributed to the fracture system largely can be eliminated.

\subsubsection{Calculation of the compaction parameter for a single well}

Well Binsh1 is used for an example here because the claycontent data from the well log curves match those from interpretations of the well logs. First, the method for characterizing clastic compaction units based on clay content was applied to identify lithological compaction units (Fig. 11a). According to the clay-content range of the classified lithological compaction units, the clay-content curves can be transferred into a lithological compaction unit curve (Fig. 11b). The compaction recovery thicknesses for each of the different compaction units were calculated, and then the stratal thicknesses of target horizons were obtained following compaction corrections. Finally, by dividing the compaction corrected thickness by the current stratal thickness, the compaction correction degree can be obtained.

\subsubsection{Calculation and analysis of compaction recovered thickness}

In the same way, the compaction correction parameters for other wells were calculated on the basis of quality- controlled data. Then, the plan-view distribution map of compaction correction parameters can be obtained by employing the Kriging interpolation method (Fig. 12b).

The depth domain thickness map of member Es 2 can be obtained through time-depth conversion (Fig. 12a). By multiplying the plan-view distribution map of the compaction correction parameters by the thickness map in the depth domain, a plan-view map of the compaction recovered thickness of the $\mathrm{Es}_{2}$ member can eventually be calculated (Fig. 12c). Before applying the compaction correction, the area of well Binsh1 exhibited flat topography, similar to the topographic features of well Binsh18 (Fig. 12a). After compaction recovery (Fig. 12c), the area of well Binsh1 was used for a different topographic assessment which obviously was lower than the area of well Binsh18. It can be interpreted that the present strata thicknesses in the area of wells Binsh1 and Wellbinsh18 area are nearly the same, whereas well Binsh1 contains a greater proportion of shale layers than well Binsh18. After the application of the compaction correction, the corrected thickness of well Binsh1 was greater than that of well Binsh18; i.e., the "topography inverse" phenomenon occurs. The location of well Binsh1 can be interpreted as the center of the lake basin, which matches well with regional sedimentary features (Fig. 12d). Also, the paleo-geomorphology corresponds to depositional distribution characteristics. With the aid of the 3-D interpolated compaction correction method that is based on the parameters of the compaction correction, the precision of the compaction correction also has been improved. 


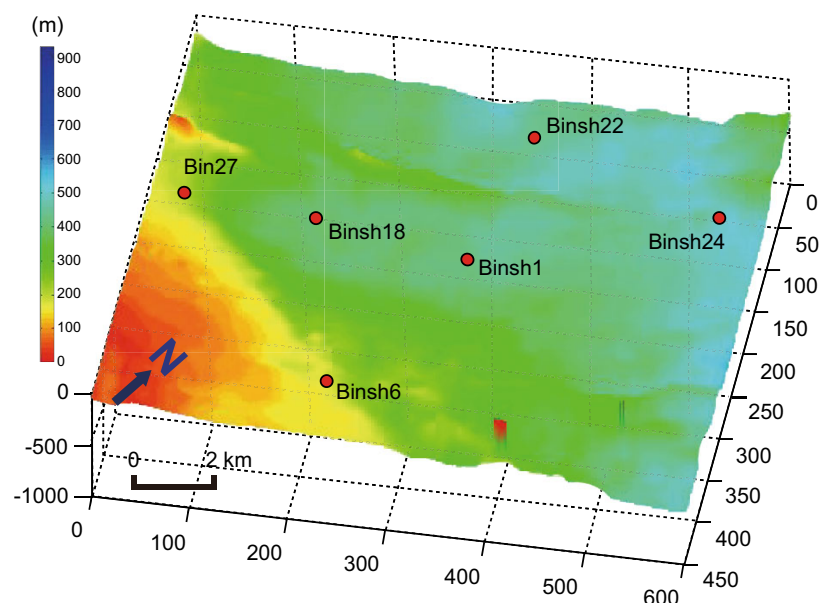

(a)

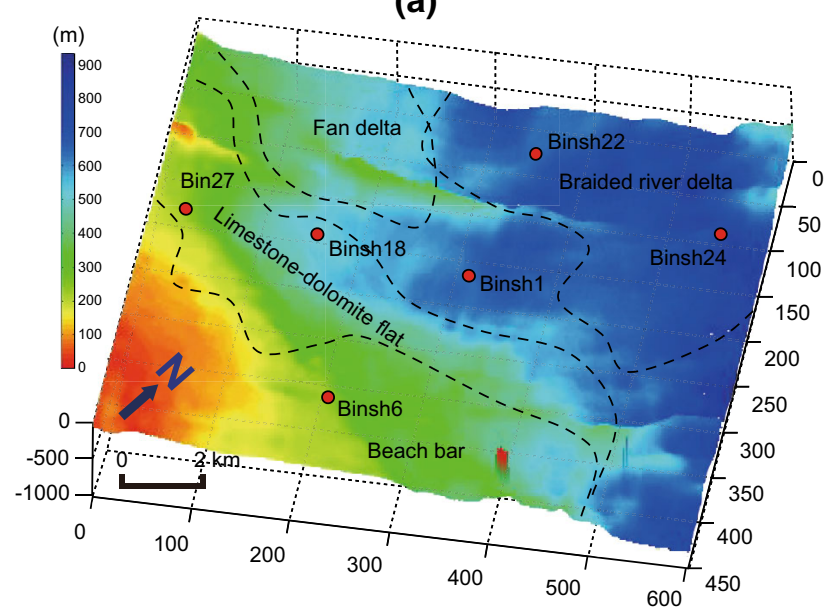

(c)

Fig. 12 Plan views of the paleo-geomorphic recovered thickness of the $\mathrm{Es}_{2}$ formation in the study area (a paleo-geomorphic thickness before compaction recovery; b plan map of compaction correction

\subsection{Comparison}

Both of proposed integrated well- and seismic-data compaction recovery methods have merits and disadvantages. The most helpful method can be chosen according to specific seismic or geological conditions and data. When the seismic or geological conditions of a clastic survey are favorable, the precision of the clay-content inversion can be guaranteed. The compaction recovery method, based on 3-D clay-content inversion data, is able to ensure the precision of compaction characterizations that are some distance away from wells. Compared with the other method based on interpolation, this method has its advantages in plan-view propagation with more reliability. Yet, as the impedance inversion, clay-content inversion, and timedepth conversion are all involved in this method, the accumulated errors cannot be ignored. Also, this method is time-consuming and complicated to conduct within an industrial research setting. However, it can be regarded for

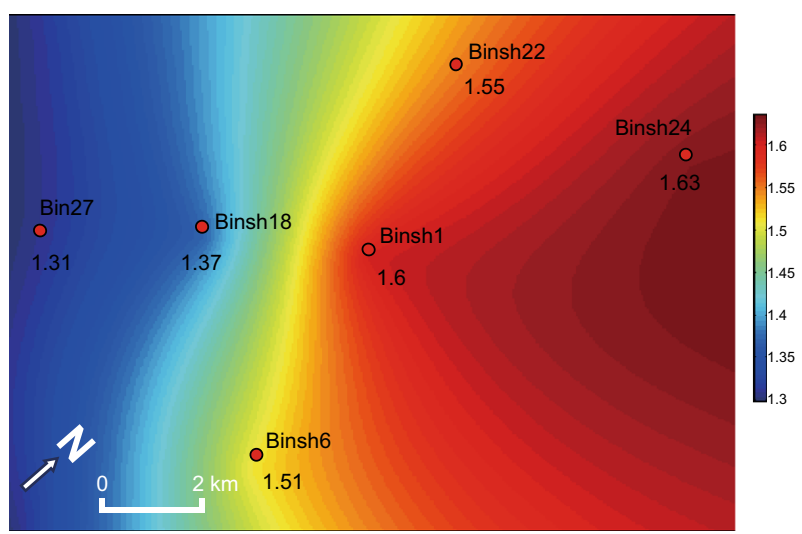

(b)

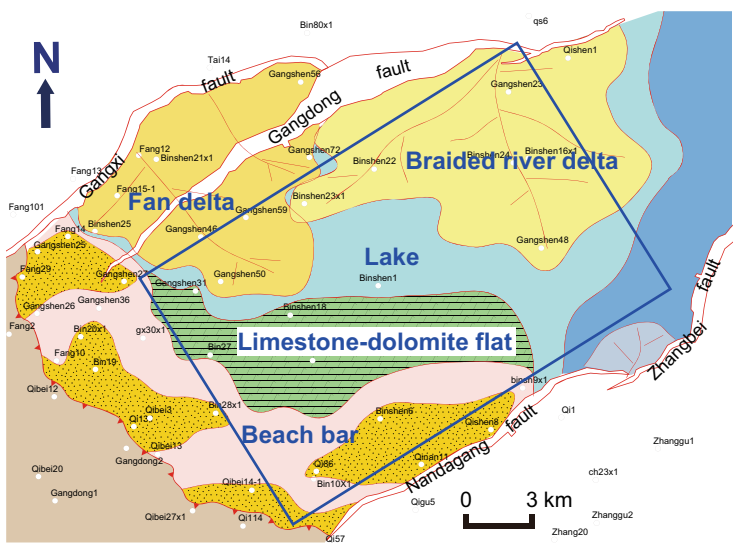

(d)

degree; c paleo-geomorphic thickness after compaction recovery; d depositional map of $\mathrm{Es}_{2}$ formation)

reference as a compaction recovery method that integrates well and seismic data.

The plane interpolation of the compaction correction method (based on compaction correction parameters) makes full use of compaction information from wells. When the number of wells is sufficient, the plan compaction characteristics derived from the interpolation method are credible. Also, as few calculation procedures are involved in this method, the accumulated errors are small. Compaction characterizations from wells largely can be retained. On the whole, this method based on the plan-view interpolation of compaction correction parameters is economical and efficient to employ—with obvious value for industrial applications.

\section{Conclusions}

(1) It is reasonable and necessary to develop a porosityclay content-depth compaction model. 
(2) The research precision of the compaction correction can be effectively improved by applying the method of classifying clastic compaction units based on clay content.

(3) The proposed compaction correction method, based on the plan-view interpolation of the compaction correction parameters, can retain and largely make full use of compaction information from wells. The geomorphological attributes closest to the real paleogeomorphology can be obtained. The efficiency and feasibility of the process make industrial applications possible.

(4) In addition to mechanical compaction, several other factors, such as the erosion effect, tectonic activity, diagenesis, and abnormal pressure, can have considerable impacts on porosity evolution. Porosity data influenced by these factors should be excluded in the study. Also, a compaction recovery method that can only consider mechanical compaction oversimplifies the compaction process. The precision of the compaction recovery work is inevitably influenced. When more data are involved (e.g., geochemical data), the recovered topography that is closer to the real paleo-geomorphology can possibly be obtained.

Acknowledgements We thank Dr. Tapan Mukerji from the Geophysics Department at Stanford University for his constructive suggestions. We particularly appreciate his great help and guidance.

Open Access This article is distributed under the terms of the Creative Commons Attribution 4.0 International License (http://crea tivecommons.org/licenses/by/4.0/), which permits unrestricted use, distribution, and reproduction in any medium, provided you give appropriate credit to the original author(s) and the source, provide a link to the Creative Commons license, and indicate if changes were made.

\section{References}

Alberts L, Weltje GJ. Predicting initial porosity as a function of grainsize distribution from simulations of random sphere packs, IAMG Conference, paper. 2001.

Athy LF. Density, porosity, and compaction of sedimentary rocks. AAPG Bull. 1930;14(1):1-24.

Atkins JE, McBride EF. Porosity and packing of Holocene river, dune and beach sands. AAPG Bull. 1992;76(3):339-55.

Beard DC, Weyl PK. Influence of texture on porosity and permeability of unconsolidated sand. AAPG Bull. 1973;57(2):349-69.
Dvorkin J, Gutierrez MA, Grana D. Seismic reflections of rock properties. Cambridge: Cambridge University Press; 2014.

Falvey DA, Middleton MF. Passive continental margins: evidence for a prebreakup deep crustal metamorphic subsidence mechanism. Oceanol Acta. 1981;4:103-14.

Fawad M, Mondol NH, Jahren J. Mechanical compaction and ultrasonic velocity of sands with different texture and mineralogical composition. Geophys Prospect. 2011;59(4):697-720.

Gui BL. The paleo-geomorphologic reconstruction of $\mathrm{Es}_{2}$ in Zhuangxi area, Bohai Bay Basin. Master of Science thesis. Beijing: China University of Geosciences; 2008. (in Chinese)

Harbaugh JW, Watney WL, Rankey EC, et al. Numerical experiments in stratigraphy: recent advances in stratigraphic and sedimentologic computer simulations. SEPM Special Publication. 1999. No. 62.

He JQ, Zhou ZY, Jiang XG. Optimum estimation of the amount of erosion by porosity data. Pet Geol Exp. 2002;24(6):561-4 (in Chinese).

Li CL, Kong XY. A new equation of porosity-depth curve. Xinjiang Pet Geol. 2001;22(2):152 (in Chinese).

Li SH, Wu CL, Wu JF. A new method for compaction correction. Pet Geol Exp. 2000;22(2):110-3 (in Chinese).

Li SH. The compaction correction based on the principle keeping formation grain volume and mass constant. Pet Geol Exp. 2001;23(3):357-60 (in Chinese).

Mavko G, Mukerji T, Dvorkin J. The rock physics handbook. Cambridge: Cambridge University Press; 2009.

Pedersen BK, Norda K. Petrophysical evalutation of thin beds: a review of the Thomas-Stieber approach. Course 24034 Report. Norwegian University of Science and Technology. 1999.

Pryor WA. Permeability-porosity patterns and variations in some Holocene sand bodies. AAPG Bull. 1973;57(1):162-89.

Qi JH, Yang Q. A discussion about the method of decomposition correction. Pet Geol Exp. 2001;23(3):351-6 (in Chinese).

Ramm M, Bjørlykke K. Porosity/depth trends in reservoir sandstones: assessing the quantitative effects of varying pore-pressure, temperature history and mineralogy, Norwegian shelf data. Clay Miner. 1994;29(4):475-90.

Schon JH. Physical properties of rocks: fundamentals and principles of petrophysics. Amsterdam: Elsevier; 2004.

Syvitski JPR, Bahr DB. Numerical models of marine sediment transport and deposition. Comput Geosci. 2001;27(6):617-8.

Thomas EC, Stieber SJ. The distribution of shale in sandstone and its effect upon porosity. In: Transactions of the 16th auunal logging symposium of the SPWLA, paper T. 1975.

Thomas EC, Stieber SJ. Log derived shale distributions in sandstone and its effect upon porosity, water saturation, and permeability. In: Transactions of the 6th formation evaluation symposium of the canadian well logging society. 1977.

Yang Q, Qi JF. Method of delaminated decompaction correction. Pet Geol Exp. 2003;25(2):206-10 (in Chinese).

Yin H. Acoustic velocity and attenuation of rocks: isotropy, intrinsic anisotropy, and stress-induced anisotropy. Ph.D. thesis. Stanford University. 1992.

Zaimy SS, Rasaei MR. Reconstruction of porosity distribution for history matching using genetic algorithm. Pet Sci Technol. 2013;31(11):1145-11158. 